УАK 004:002

ББК 73

DOI 10.22394/1682-2358-2018-2-140-149

A.I. Prokofieva, master's student of the Regional Economy and Management Department, Ufa State Petroleum Technological University

\section{EFFECTIVENESS \\ EVALUATION \\ OF STATE \\ AND MUNICIPAL SERVICES DELIVERY AT THE PREMISES OF THE MFC IN RUSSIAN REGIONS}

The article assesses the effectiveness of the provision of state and municipal services at the premises of the multifunctional centers for provision of state and municipal sevices (MFC) in the Republic of Bashkortostan, Altai Krai, and the Pskov Region in order to identify problematic aspects and develop directions for their solution. The problems of governance in the field of public and municipal services provision are analyzed.

Key words and word-combinations: state and municipal services, multifunctional centers, management.
А.И. ПрокофьеВа, махистрант кафедрь региональной экономики и управления Уфимского государственного нефтяного технического униBepcumema

(email: Afina0258@yandex.ru)

\section{ОЦЕНКА ЭФФЕКТИВНОСТИ ПРЕАОСТАВАЕНИЯ ГОСУААРСТВЕННЫХ И МУНИЦИПААЬНЫХ УСАУГ НА БАЗЕ МФЦ В РЕГИОНАХ РОССИИ}

\begin{abstract}
Аннотация. Проводится оценка эффективности предоставления государственных и муниципальных услуг на базе многофункциональных центров в Республике Башкортостан, Алтайском крае, а также Псковской области в целях выявления проблемных аспектов и разработки направлений их решения. Анализируются проблемы управления в области предоставления государственных и муниципальных услуг.

Ключевые слова и словосочетания: государственные и муниципальные услуги, многофункциональные центры, управление.
\end{abstract}

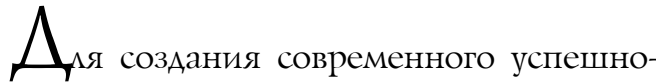
го государства, способного быстро реагировать на внешние экономико-политические процессы, важно не только правильно оптимизировать экономическую политику, но и выстраивать соответствующую спещифике и масштабам страны систему государственного и муниџипального управления, быть восприимчивым к прогрессивным технологическим и коммуникационным решениям,
\end{abstract}


но самое главное - отвечать потребностям общества и повышать уровень жизни населения, используя все имеющиеся механизмы. ОАним из таких механизмов в Российской Федераџии выступают государственные и муниџипальные услуги. Проблемы доступности и качества государственных и муниципальных услуг сегодня достаточно актуальны [1, с. 41] .

В 2010 г. был принят Федеральный закон № 210-Ф3 «Об организации преАоставления государственных и муниципальных услуг», который, по сути, стал первым законодательным актом в отечественной нормативно-правовой базе, направленным на обеспечение прав граждан при обращении в государственные и муниципальные органы. Аанный Закон обозначим основные направления оптимизации предоставлении государственных и муниципацьных услуг, а также кмючевые понятия и направцения развития.

Законом закрепиены следующие положения:

1. Государственная услуга - это предоставляемая федеральным органом исполнительной вмасти, органами государственного внебюАжетного фондов, исполнительными органами государственной власти субъекта РФ, а также органами местного самоуправцения (МСУ) при осуществлении государственных полномочий (переданных федеральными законами и законами субъектов РФ), Аеятельность по реализации функций федерального органа исполнительной власти, государственного внебюджетного фонда, исполнительного органа государственной власти субъекта РФ, а также органа МСУ при осуществлении некоторых государственных полномочий, низложенных федеральными законами и законами субъектов РФ, которая предоставляется по запросу заявителей в пределах, установленных нормативами правового акта РФ и нормативами правового акта субъектов РФ, предоставцяющих государственные услуги [2] .

2. Муниџипальная услуга - это предоставцяемая органами МСУ Аеятельность по реализации функций органа МСУ, осуществцяемая по запросу заявителей в пределах компетенции полномочий органа, предоставцяющего муниципацьные услуги, по оказанию вопросов местного значения, в соответствии с Федеральным законом от 6 октября 2003 г. № 131-Ф3 «Об общих принципах организации местного самоуправления в Российской Федерации» и в соответствии с уставами муниципамьных образований [2] .

Под государственной и муниџипацьной услугой понимают мюбую Аеятельность, входящую в компетенцию государственных и муниципальных органов, и поводом Аля выполнения которой явцяется обращение конкретного юриАического или физического миџа. Иначе говоря, ускуги медицинских, образовательных, и прочих соџиальных учреждений - это услуги, предоставцяемые государственными ици муниџипальными (бюджетными, автономными и казенными) учрежкдениями.

Органы вмасти оказывают юридическим циџам (организациям) и гражданам большое количество услуг: оформление паспорта, прав на недвижимость и земельный участок, регистрация автомобиля, прием налоговой Аекмарации, оформление пенсии, регистрация брака, Аетей, ежемесячных пособий, получение справок и оформление мицензий и многие Аругие. 
Получателем государственной или муниципальной услуги явмяется физическое или юридическое миџо (за искмючением государственных органов и их территориальных органов, органов государственных внебюджетных фонАов и их территориальных органов, органов МСУ) мибо их уполномоченные представители, обратившиеся в орган, предоставляющий государственные или муниџипальные услуги, с запросом о предоставлении ускуги, выраженным в устной, письменной или электронной форме [2] .

Немаловажной задачей административной реформы в Российской Федерации выступает наведение порядка в сфере государственного и муниципального управмения, а также повышение качества государственных и мунищипальных услуг.

ГАавной џемью разработки направлений совершенствования государственного регулирования является создание «компактного», «сервисно-ориентированного государства», то есть государство обеспечивает права и свободу граждан и гарантирует высокое качество предоставления государственных и муниципальных услуг Аля решения их проблем и ограничивает сферу своего влияния. Государственные и муниџипальные услуги - одна из наиболее конфликтных зон взаимоотношения государства и граждан, и ее нужно изучать и регулировать. Услуги, предоставляемые государственными и муниципальными учреждениями, в которых размещаются государственные и муниципальные задания, подлежат вкмючению в реестр государственных и муниципальных услуг и Аолжны предоставляться в электронной форме.

Организаџия конџептуально нового подхода к проџессу предоставления государственных и муниципальных услуг в режиме «одного окна» через сеть многофункциональных центров (МФЦ), а также перевод проџесса в электронный формат позволили значительно упростить диалог государства и насемения, сделать процесс более простым и понятным, сократить временные рамки и финансовые издержки. Благодаря проводимым реформам удалость повысить степень доверия общества к власти [3, с. 480].

МФЦ - это государственное или муниципальное учреждение, предназначенное отвечающим требованиям, установленным федеральным законодательством и Правительством РФ с функциями уполномоченного дмя организации предоставления государственных и муниџипальных услуг по принципу «оАного окна». От гражАанина требуется только подать заявление и в установленный срок получить результат, а всю оставшуюся работу должны проводить сотрудники МФЦ, а также соответствующие государственные и муниципальные органы власти. Сегодня взаимодействие получателями государственных и муниџипальных услуг с органами государственной власти производится кично, с помощью электронной почты, по телефону, через информационные киоски (инфоматы), расположенные в МФЦ, а также с помощью Интернета.

В цемях реализации Федерального закона № 210-ФЗ от 27 июля 2010 г. «Об организации предоставления государственных и муниципальных услуг» постановлением Правительства Республики Башкортостан от 28 октября 2011 г. № 380 (в реА. от 1 апреля 2015 г.) была разработана и утверждена целевая программа «Снижение административных барьеров, оптимизация и повышение качества предоставления государственных и муниципальных услуг, в том 
числе на базе многофункщиональных центров предоставления государственных и муниџипальных услуг, на 2011-2014 годы» (Цемевая программа), одной из задач которой стало создание соответствующих установленным требованиям филиалов и отделений республиканского государственного автономного учреждения Многофункциональный центр предоставления государственных и муниципальных услуг (РГАУ МФЦ) [4] .

В период разработки Целевой программы в Башкортостане уже велась работа по подготовке системы административных регламентов предоставления государственных ускуг исполнительными органами государственной вцасти. ОАнако отсутствие комплексного подхода к решению вопроса созАания центров обслуживания насемения и организаций приводияо к невозможности установления единых стандартов предоставления государственных и муниципальных услуг; усложняло регламентные процедуры осуществления межведомственных согласований в ходе оформления и подготовки к выдаче документов заявителям; увеличивало продолжительность предоставления услуг; Аелало невозможным получение различных услуг в единовременном порядке и в оАном месте; повышало вероятность совершения коррупџионных действий сотрудниками республиканских органов исполнительной власти, органов МСУ Республики в ходе работы с получателями государственных и муниципальных услуг; создавало транспортные и иные неудобства получателям услуг.

Все это обусловливало принятие решения о проведении оптимизаџии процесса предоставления государственных и мунищипальных услуг. В месячный срок переА Министерством экономического развития Республики были поставлены задачи по утверждению Устава РГАУ МФЦ, назначению руководителя, а также закреплению за РГАУ МФЦ недвижимого и особо ценного Авижимого имущества.

В 2012 г. в Уфе был открыт центральный офис РГАУ МФЦ с количеством окон обслуживания насемения 30 еАиниц. На момент открытия РГАУ МФЦ предоставляло 61 услугу. К конщу 2013 г. филиальная сеть РГАУ МФЦ насчитывала пятнадџать офисов в семи городах и семи селах республики, включая Ава офиса в городе Уфе. За 2013 г. в офисы РГАУ МФЦ обратилось порядка 500 тыс. граждан. В 2014 г. были введены в работу еще девять офисов РГАУ МФЦ в городах Уфа, Мемеуз, Аавлеканово, Янаул, Сибай, Бемореџк, а также селах Чекмагуш, Буздяк, Месягутово. Количество предоставмяемых услуг возросло до 538. Услугами сети РГАУ МФЦ на тот момент воспользовались 1500000 чемовек [5].

В связи с возросшей популярностью центров МФЦ и расширением перечня предоставляемых услуг увеличилась нагрузка на специалистов, принимающих заявителей, и соответственно - время ожидания в очереди, что вызвало неАовольство среди населения. Остро обозначилась проблема нехватки Аополнительных офисов. К началу 2015 г. развитие филиальной сети МФЦ было временно приостановлено в связи с нехваткой финансирования и отсутствием заинтересованности в развитии сети со стороны учредительных органов. Фактически это грозияо Правительству Республики нарушению в части исполнения Указа Президента РФ. ОАнако за последующие 6 месяџев удалось 
запустить еще 48 офисов. Этому способствовала глобальная кадровая реформа в Минэкономразвития. Так, за 2015 г. количество обратившихся за получением государственных и муниципальных услуг граждан перешагнуло за отметку в 2,5 мин чел. Аинамика количества обращений в РГАУ МФЦ за периоА 2012-2015 гг. представлена на рис. 1 [5].

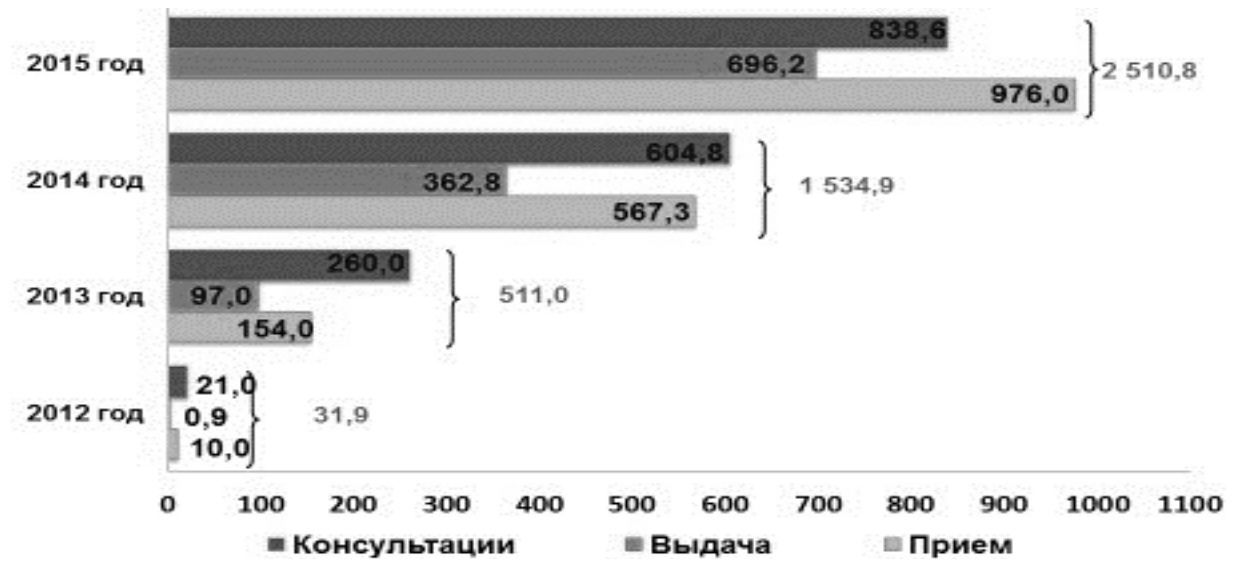

Рис. 1. Аинамика количества обращений в РГАУ МФЦ в 2012-2015 гг., тыс. еАиниц

К началу 2016 г. филиальная сеть РГАУ МФЦ насчитывала 73 офиса МФЦ и 492 территориально обособленных структурных подразделений с количеством окон обслуживания не более одного во всех муниџипалитетах региона. По состоянию на 1 января 2016 г., доля граждан, имеющих доступ к получению услуг по принципу «одного окна» в Республике составила 98,4\%. Усмуги, предоставление которых было организовано в РГАУ МФЦ, и количество органов власти, с которыми взаимодействовало РГАУ МФЦ по состоянию на 1 января 2016 г., представлены на рис. 2 [5].
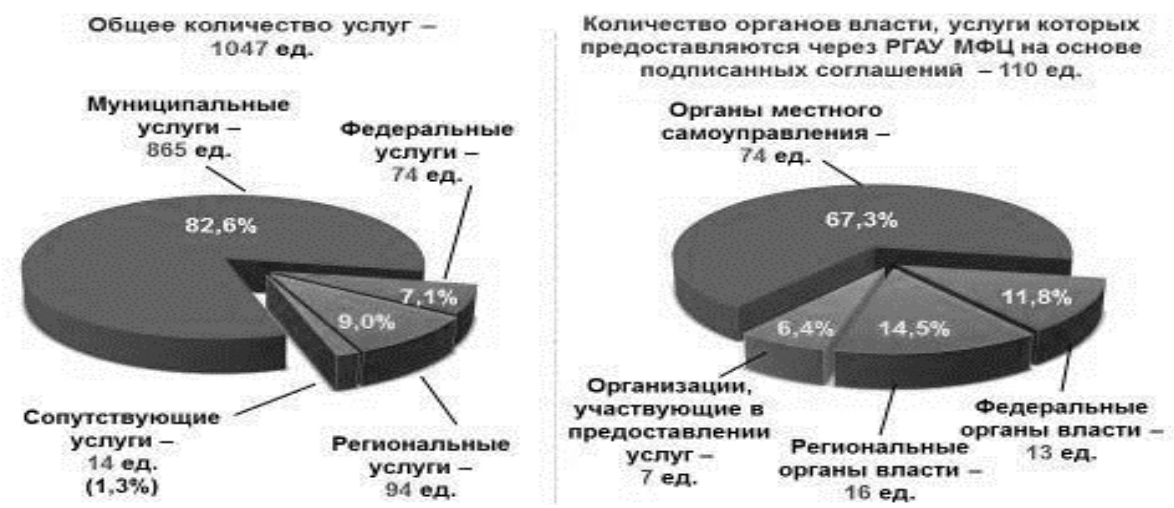

Рис. 2. Взаимодействие РГАУ МФЩ с органами вмасти по части предоставления услуг на 1 января 2016 г. 
К началу 2017 г. были введены в работу еще два офиса МФЦ в г. Уфе. Степень удовлетворенности граждан получением государственных и муниципальных услуг через офисы МФЦ на начало 2017 г. составика 99,8\%, что свидетельствует об удовлетворенности населения проведенными реформами в системе государственного управления, в том числе по части предоставления услуг.

Таким образом, Республика Башкортостан вступика в Программу по созАанию сети МФЦ оАна из последних, однако сегодня регион кидирует по показателям охвата населения, количеству предоставцяемых услуг и степени удовцетворенности населения к качеству предоставления услуг.

Отметим, что некоторые проблемы в области управления развитием сети МФЦ в регионах сохранились, и их решение позволит повысить эффективность предоставления государственных и муниципальных услуг. В цемях эффективного выявления проблемных аспектов в организаџии предоставления услуг и управмения сетью МФЦ в регионах необходимо составмение объективного рейтинга по регионам, что позволит формулировать направления совершенствования. Проанализируем рейтинг субъектов РФ по предоставлению данных услуг.

Согласно отчету Правительства РФ, сегодня самые масштабные сети МФЦ, по данным Минэкономразвития, созданы в Москве, Московской, Ростовской областях, Краснодарском крае, Республике Башкортостан. Наряду с этим Минэкономразвития России опубликовало рейтинг регионов по организаџии преАоставления государственных и муниџипальных услуг в МФЦ по Аанным за второй квартал 2017 г., согласно которому мидером явмяется Алтайский край.

Отметим, что ежегодно на территории ААтайского края увеличивается количество принятых документов. В 2014 г., когАа МФЦ функщионировали всего в нескольких районах Алтайского края, было принято 363880 тыс. обращений от граждан; в 2016 г. - уже около 1 млн 300 тыс. Сегодня на территории Алтайского края 68 филиалов и 290 территориально обособленных структурных подразделений. Таким образом, относительно за короткий промежуток времени на территории региона была проведена значительная работа по развитию МФЦ.

ОАнако на территории Алтайского края существуют весьма острые проблемы, которые затрудняют развитие обслуживания граждан. ЗАесь высокий процент сельского населения, доля которого составцяет 44\% (в среАнем по России доля сельчан - 26\%). К тому же в регионе 59 муниципальных районов, включающих 647 сельских поселений, 1589 сельских населенных пунктов, что затрудняет посещение МФЦ, обусловленное дальностью поездок, а использование Интернета остается на низких показателях (в 2015 г. $-21,9 \%$ в селе; 43,9\% в городе) [6] .

Исходя из этого, на наш взгляА, целесообразно уделить пристальное внимание обеспечению услугами, предоставмяемыми МФЦ в сельской местности, к примеру, посредством ежемесячного выездного обслуживания специалистов в области предоставления государственных и муниципальных ускуг. Это позвоцит охватить большую часть сельчан обеспечением данных услуг и устранить трудности посещения МФЦ. 
Что касается обеспечения Интернетом сельских территорий, то, по нашему мнению, в рамках конџепџии муниџипально-частного партнерства, следует заключить соглашения по устранению цифрового неравенства с телекоммуникаџионными компаниями (к примеру, с Ростелеком), что позволит обеспечить техническую возможность скоростного доступа к сети. ПосреАством интернетизации сельских территорий можно также решить проблему с Аистанционным получением государственных и муниципальных услуг через интернет-портац «Госускуги».

В регионах с низким показателем развития сети МФЦ интересным, по нашему мнению, представляется опыт Псковской области. ЗАесь услуги обеспечивают в муниципальных районах и городских округах 24 отдела МФЦ, а также 33 территориально-обособленных структурных подраздемения в наибомее густонаселенных сельских поселениях. В 2016 г. через 119 окон обслуживания гражданами было подано в общей сложности более 132 тыс. заявлений. Среднее время ожидания в очереди составило 11 минут (в Пскове и Великих Ауках ожидание составляет от 15 до 60 минут), в связи с этим у граждан появцяются объективные претензии к МФЦ и отсутствие желания пользоваться данными ускугами, так как центр не выполняет своей главной задачи упрощать и ускорять обслуживание граждан. Наряду с этим в ряде районов в МФЦ подается всего по 1-2 заявления на каждого спеџиалиста, что не обеспечивает должной эффективности работы [7]. Основной претензией к региону является расхождение межАу первоначальным планом сети МФЦ, сформированном в 2014 г., и нынешней ситуацией. С начала 2014 г. в МФЦ обратились всего порядка 1,2 тыс. человек, охват населения услугами составиц мишь $75 \%$, что явмяется низким показателем.

Решить имеющиеся проблемы, на наш взгляА, можно следующим образом:

- создать на основе МФЦ окна Аля субъектов малого и среАнего преАпринимательства, в которых будут оказываться услуги Амя юридических киџ и индивиАуальных преАпринимателей, что позволит повысить уровень Аеловой активности и привлечет дополнительных клиентов в МФЦ;

- оснастить МФЦ платежными терминалами, что предоставит возможность приема от заявителей денежных средств в счет уплаты государственной пошлины или иной платы за предоставление государственных и муниципальных услуг. Это позвоцит существенно повысить посещаемость МФЦ;

- уделить особое внимание соџиальной рекламе по предоставлению услуг посреАством МФЦ, что позволит населению региона узнать о преимушествах обращения в подобные центры;

- рассмотреть вариант с закрытием нерентабельных отделений МФЦ с Аальнейшей передачей полномочий по приему Аокументов другим филиалам;

- в цемях устранения очередей целесообразно предоставмять возможность получения ускуги посреАством портала «Госуслуги» через терминалы, установменные в отдемениях МФЦ; разграничить полномочий сотрудников, выделив из них группы консультантов по порядку предоставления ускуг и специа-

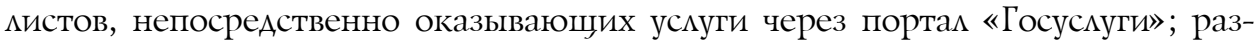
делить рабочие дни недели специалистов на Ани приема документов и дни консультаций. 
Используя данные, размещенные на официальных сайтах МФЦ в Респубмике Башкортостан, Алтайском крае и Псковской области, сравним Республику Башкортостан, которая в рейтинге показателей занимает промежуточное место, с А^тайским краем, мидером рейтинга, и Псковской областью, которая находится в блоке низкой эффективности. Подробная информация представмена в таблице.

Показатели развития МФЦ среди субъектов РФ по годам

\begin{tabular}{l|c|c|c|c}
\hline \multirow{2}{*}{\multicolumn{1}{c|}{ Субъект }} & \multicolumn{2}{|c|}{$\begin{array}{c}\text { Динамика количества обращений } \\
\text { (заявлений) }\end{array}$} & \multicolumn{2}{|c}{$\begin{array}{c}\text { Количество МФЦ } \\
\text { (офисов) }\end{array}$} \\
\cline { 1 - 5 } & 2014 & 2016 & 2014 & 2016 \\
\hline Алтайский край & 363880 & 1300000 & 17 & 68 \\
Республика Башкортостан & 1500000 & 4100000 & 24 & 73 \\
Псковская область & 1200 & 132000 & 13 & 57
\end{tabular}

Исходя из данных таблиџы видно, что по количеству обращений Респубмика Башкортостан, безусловно, является мидером, так как на территории региона наибольшее количество офисов МФЦ, а удовлетворенность населения услугами составмяет 96,67\%, что превышает нормативное значение. Высочайших значений удалось достичь благодаря тому, что Республика вошла в число 39 субъектов РФ, принимающих участие в пилотном проекте Минэкономразвития России по организации деятельности МФЦ, ориентированных на предоставление государственных, муниџипальных, дополнительных (сопутствующих) услуг субъектам преАпринимательства.

Несмотря на гораздо меньшее количество обращений в МФЦ, а также меньшее количество офисов на территории Алтайского края, регион является несомненным Аидером по развитию МФЦ и предоставлению услуг населению. По нашему мнению, достижению таких результатов, безусловно, способствовал тот факт, что Алтайский край в 2014 г. вошел в число пилотных регионов, которые занимались внеАрением единого фирменного стиля МФЦ (зоны ожиАания, детские комнаты, решения дяя посешения центров маломобимьными гражАанами). В Псковской области, по данным таблиџы, количество обращений как в 2014, так и в 2016 г. оставались низкими несмотря на открытие новых офисов. Система обеспечения деятельности МФЦ, которая в настоящее время используется регионом, не удовлетворяет рялу требований, вдобавок производитель прекратил ее подлерживать, что и обусловливает крайне низкую позицию в рейтинге, а также неудовлетворенность населения.

Итак, несмотря на очевидное мидерство по количеству обрашений гражАан за государственными и муниципальными услугами, а также количеству офисов Республика Башкортостан не занимает мидирующей позиции. Очевидно, что те регионы, где проживает больше граждан, явцяются и регионами-лидерами по размеру созданных на их территориях сетей МФЦ, хотя это, конечно, требует от них и сушественных затрат. 
Полагаем, Башкирия обцадает всем набором необходимых качеств дмя того, чтобы быть абсолютным мидером в рейтинге эффективности регионов. По финансовому обеспечению деятельности МФЦ она является одним из лидеров по доходам от перераспределения госпошиины среди субъектов РФ (Федеральный закон № 406-Ф3 «Распределение платы за предоставление госуАарственных и муниџипальных услуг по аналогии с перераспределением госпошиины»). Субъектами РФ с наибольшим доходом явцяются следующие: Московская область - 170,7 млн руб.; г. Санкт-Петербург - 155,8 млн руб.; г. Москва - 116,1 млн руб.; Свердмовская область - 108,9 млн руб.; Республика Татарстан - 105,8 млн руб.; Республика Башкортостан - 94,4 ммн. руб. [8]. При составлении рейтинга субъектов необходимо учитывать и данное обстоятельство.

На наш взгляд, в дальнейшем Минэкономразвитию необходимо модернизировать методику составления рейтинга субъектов, поскольку она не отражает оценки заявителей и не ориентирована на их интересы.

Советник руководителя Аепартамента информационных технологий (АИТ) Москвы А. Белозеров отмечает, что сегодня имеются два федеральных рейтинга - Минэкономразвития РФ и Минкомсвязи РФ: «В обоих вроде бы оџенивается одно и то же, но подход разный, и результаты вообще никак не бьются. Вместо стимулирования получаем разобщение регионов и размывание государственной политики в этом вопросе. Рейтинг Минэка, на мой взгляА, страдает формализмом. К примеру, он фиксирует наличие электронной записи, но саму услугу заявители уже Аавно получают в МФЦ в момент обращения ици полностью в эмектронном виде на интернет-порталах, соответственно, никакая запись не требуется. Рейтинги, как минимум, не должны наказывать регионы, которые продвинулись дальше обязательной программы» [9] .

Основным направлением развития рейтинга субъектов РФ должно выступать повышение достоверности данных, на которых он основывается, а также сокращение сроков сбора информаџии. Опыт реализаџии приоритетных национальных проектов однозначно подтвердил крайнюю актуальность задачи создания в максимально короткий срок государственной системы, обеспечивающей информационную подАержку заинтересованным органам ваасти - от президента до руководителей муниџипальных образований - на всех этапах управления - от планирования до контроля и прогнозирования результатов.

В ходе реализаџии государственной программы Российской Федерации «Информационное общество (2011-2020 годы)» органами исполнительной власти Республики Башкортостан успешно выполняются следуюшие мероприятия по использованию информаџионно-коммуникаџионных технологий в образовании, зАравоохранении, Аля повышения качества предоставления государственных и муниџипальных услуг насемению:

- организован центр обработки данных, на котором развернута региональная медицинская информационно-аналитическая система;

- до мечебных учреждений доведены оптоволоконные минии связи Аля объединения в закрытую сеть передачи данных;

- внедрена информаџионная система паспортизаџии учреждений зАравоохранения. 
В связи с этим, по нашему мнению, актуальным явмяется создание и внеАрение в деятельность МФЦ Единой информационно-аналитической системы управления предоставлением государственных и муниџипальных услуг. Информационно-аналитический подхоА позволит не только решить задачу госуАарственного управления, но и, что немаловажно, обеспечить оџенку эффективности деятельности конкретных МФЦ по их реализации, а также сократит сроки сбора и обработки информации.

Необходимость автоматизаџии проџессов информаџионного обеспечения управления МФЦ обусловлена отсутствием эффективной методики рейтингирования субъектов, достоверности информаџии, а также организаџионной и территориальной рассредоточенностью органов исполнительной вмасти и МФЦ [10, с. 98]. ВнеАрение такой системы создает условия автоматизации процессов сбора, обработки и представления информаџии, необходимой органам государственной власти Аля обеспечения эффективного управления деятельностью МФЦ, создания объективного рейтинга субъектов предоставления государственных и муниџипальных услуг, обеспечит невмешательство МФЦ в оџенку заявителем получения подобного рода услуг.

Таким образом, сегодня еще имеются нерешенные проблемы в области управления предоставлением государственных и муниципальных услуг, заключающиеся в неэффективном и необъективном составлении рейтинга субъектов предоставления государственных и муниципальных услуг. Аанную проблему призвано решить информационно-аналитическое управление, которое должно стать неотьемлемой частью государственного управления, способного обеспечивать эффективное развитие соџиально-экономических проџессов. Современное развитие соџиально-экономического общества тесно связано с развивающимися интернет-технологиями, помонающими органам власти и учреждениям оказывать качественные, востребованные и доступные услуги.

\section{Библиографический список}

1. Сабирова 3.Э. Экономика общественного сектора: учебное пособие. Уфа, 2015.

2. Об организации предоставления государственных и муниципальных услуг: Федер. закон от 27 июля 2010 г. № 210-ФЗ (в ред. от 28 дек. 2016 г.). URL: http://www.consultant.ru/ document/cons_doc_LAW_103023/

3. Яхин Д.И. О предоставлении муниципальных услуг через многофункциональные центры предоставления государственных и муниципальных услуг // Студенческая наука и XXI век. 2017. № 14. С. 480-481.

4. О республиканской целевой программе «Снижение административных барьеров, оптимизация и повышение качества предоставления государственных и муниципальных услуг, в том числе на базе многофункциональных центров предоставления государственных и муниципальных услуг на 2011-2014 годы»: постановление Правительства Республики Башкортостан от 28 окт. 2011 г. № 380 (в ред. от 1 апр. 2015 г.). URL: http://docs.cntd.ru/document/463515231

5. МФЦ Башкортостан. URL: https://mfcrb.ru/

6. КАУ «МФЦ Алтайского края». URL: https://mfc22.ru/

7. МФЦ Псковской области. URL: http://mfc.pskov.ru/web/guest;jsessionid=94cf9440cee01d

8. Официальный сайт Министерства экономического развития Российской Федерации. URL: http://economy.gov.ru/minec/about/structure/dknrd/2016030102

9. Прокофьева А.И. Информационно-аналитическое обеспечение управления приоритетными национальными проектами // Наука через призму времени. 2018. № 1 (10). С. 97-99. 